Review

\title{
Advances in the production technology of hydrogen peroxide
}

\author{
Guohua Gao, Yanan Tian, Xiaoxiao Gong, Zhiyong Pan, Keyong Yang, Baoning Zong * \\ Research Institute of Petroleum Processing, Sinopec, Beijing 100083, China
}

\section{A R T I C L E I N F}

\section{Article history:}

Received 12 October 2019

Accepted 4 December 2019

Published 5 July 2020

\section{Keywords:}

Hydrogen peroxide

Anthraquinone auto-oxidation

Hydrogenation of anthraquinone

Hydrogenation catalyst

Production Technology

\begin{abstract}
A B S T R A C T
This article mainly summarizes various aspects of hydrogen peroxide $\left(\mathrm{H}_{2} \mathrm{O}_{2}\right)$ production through the anthraquinone route, including hydrogenation catalysts, working solution, regeneration technique, hydrogenation reactors, and environmental protection. The advances and breakthrough of SINOPEC in the production of $\mathrm{H}_{2} \mathrm{O}_{2}$ through the anthraquinone route is presented in this review, highlighting recent innovative technology on these aspects developed independently. The technical prospect and scientific challenges associated with the direct synthesis method from hydrogen and oxygen are also briefly discussed.
\end{abstract}

(C) 2020, Dalian Institute of Chemical Physics, Chinese Academy of Sciences. Published by Elsevier B.V. All rights reserved.

\section{Introduction}

Hydrogen peroxide is widely used as an oxidant, a bleaching agent, disinfectant, and polymer initiator and crosslinker in various fields, such as papermaking, textile, chemical synthesis, military, electronics, food, drugs, cosmetics, environment protection, and metallurgy. The global consumption of hydrogen peroxide as of 2018 was about 6.5 million metric tons and the value has been increasing rapidly since then, with a domestic market share of more than 50\%.

Electrolysis, anthraquinone (AQ) auto-oxidation (AO), isopropanol oxidation, and electrochemical cathode reduction of oxygen [1-3] are commonly used in the production of hydrogen peroxide. The AO method has prominent advantages, including its low consumption, low cost, and convenience for equipment scale-up. Thus far, hydrogen peroxide production through the AO method accounts for $95 \%$ and $99 \%$ of global and domestic production, respectively [4]. This method will remain prevalent for some time before the emergence of more advanced technology.
The main procedures of the AO method include AQ hydroperoxide extraction, and working solution purification and recycling (Fig. 1). The working solution is obtained by dissolving $\mathrm{AQ}$ in organic solvents (see the third section), where $\mathrm{AQ}$ is converted to AHQ in the presence of a hydrogenation catalyst. Subsequently, after separation of the catalyst, AHQ is oxidized back to $\mathrm{AQ}$ with the formation of equimolar hydrogen peroxide. Crude hydrogen peroxide obtained through water extraction must be further purified to meet the market demand. In addition, the degradation of $A Q$ is inevitable in both the hydrogenation and oxidation processes, and it negatively affects industrial production. Therefore, the working solution must be post-treated before recycling $[5,6]$ in the AO method.

Hydrogenation of $\mathrm{AQ}$ is the key process in the production of the product yield and production efficiency of the equipment. Domestic and foreign experts have conducted extensive research on the catalyst, working solution, and reaction technologies. Several companies with the largest production capacity genation, anthrahydroquinone (AHQ) oxidation, hydrogen hydrogen peroxide through the AO method, directly affecting

\footnotetext{
* Corresponding author. Tel: +86-10-82368011; E-mail: zongbn.ripp@sinopec.com This work was supported by the National Key Research and Development Program of China (2016YFB0301600). DOI: 10.1016/S1872-2067(20)63562-8 | http://www.sciencedirect.com/science/journal/18722067 | Chin. J. Catal., Vol. 41, No. 7, July 2020
} 


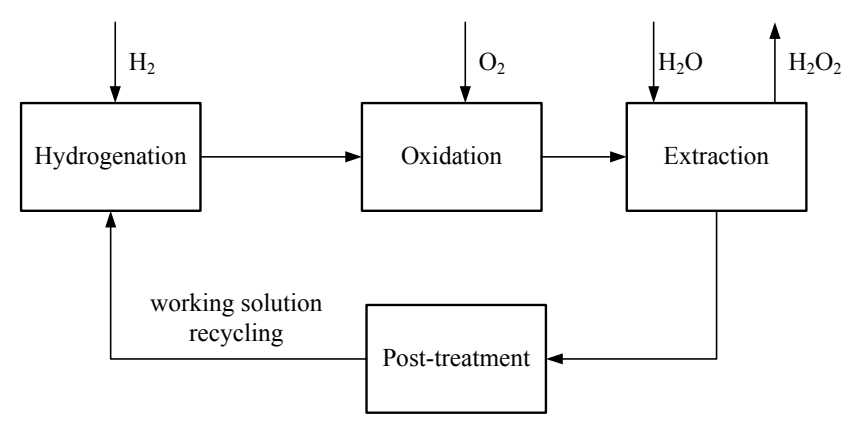

Fig. 1. Flow diagram of the AO method.

of hydrogen peroxide in the world also have their original technologies and related production plants. SINOPEC Research Institute of Petroleum Processing (RIPP) studied and developed core technologies in the AO method, particularly for catalysts, regeneration of the working solution, hydrogenation reactor, and environmental protection. In addition, RIPP has made significant breakthroughs in the $\mathrm{AO}$ method and done a great deal of work on the basic research and technique planning of future technology in the production of hydrogen peroxide, namely the direct synthesis from hydrogen and oxygen.

\section{Anthraquinone hydrogenation catalyst}

In the $\mathrm{AO}$ method, the hydrogenation catalyst is the key factor, directly affecting the economics and product quality of hydrogen peroxide. The catalysts should exhibit good selectivity and stability in both fixed-bed and slurry-bed technologies. Low selectivity of the catalyst will increase the production cost, exert a negative effect on continuous production, and reduce the project economics greatly. On the one hand, low selectivity aggravates side reactions, which produces additional degradation products with higher hydrogen consumption than the theoretical value. On the other hand, the loss of AQ in the working solution would increase, once the degradation products formed fail to be restored to AQs; additionally, the catalyst stability would be seriously affected if the degradation products with relatively low solubility are adsorbed on the catalyst.

Among Ni-based catalysts, Raney $\mathrm{Ni}$ is the most widely used due to its high activity and selectivity. However, the hydrogenation reactor has a complicated structure, and Raney $\mathrm{Ni}$ is inclined to self-ignite in air. Once Raney Ni is deactivated, it is rather difficult for catalyst regeneration to occur. Besides, the catalyst is also extremely sensitive to trace $\mathrm{H}_{2} \mathrm{O}_{2}$ and $\mathrm{O}_{2}$ in the working solution. Therefore, Raney $\mathrm{Ni}$ has been replaced by the Pd catalyst in commercial units [23].

The hydrogenation processes of AQs can be categorized into a fixed-bed process and a slurry-bed process. The fixed-bed reactor is a rather mature technology used in domestic industries. The egg-shelled $\mathrm{Pd} / \mathrm{Al}_{2} \mathrm{O}_{3}$ catalyst with the particle size in the range of 3-5 $\mathrm{mm}$ [7] is mostly adopted. The catalyst is regenerated every 4-6 months with steam. Compared to the characteristics of plug flow in the fixed-bed reactor, the operation condition of the complete-mixing flow in the slurry-bed reactor is beneficial for homogeneous reactions. According to chemical reaction kinetics, the concentration distribution in a CSTR slurry-bed reactor is the same as that at the outlet of the PFR fixed-bed reactor, which means that enhanced selectivity is achieved in the slurry-bed process. Due to different concerns and merits, different types of hydrogenation catalysts have been developed and applied. DuPont developed $\mathrm{Pd} / \mathrm{Al}_{2} \mathrm{O}_{3}$ and $\mathrm{Pd} / \mathrm{SiO}_{2}$ microspherical catalysts in succession with extensive application in the industry [8,9]. MGC also developed a Pd catalyst supported on $\mathrm{SiO}_{2}$ [10]. Yamaguchi et al. [11] used $\mathrm{Al}_{2} \mathrm{O}_{3}-\mathrm{SiO}_{2}-\mathrm{MgO}$ as catalyst support. Solvay [12] developed $\mathrm{Al}_{2} \mathrm{O}_{3}-\mathrm{ZrO}_{2}$ as support for the microspherical catalyst. Degussa applied an unsupported Pd catalyst in a slurry reactor [13]. Catalysts using $\mathrm{Al}_{2} \mathrm{O}_{3}$ as the support have enhanced mechanical strength, stability, and high dispersion, although they have poor selectivity and strong promotion effect on the formation of the degradation products. Catalysts supported on $\mathrm{SiO}_{2}$ are beneficial to reduce the amount of degradation products [14]; however, their relatively low Pd loading is more likely to result in $\mathrm{Pd}$ leaking. When using an unsupported Pd catalyst, there is no issue of deactivation caused by serious pore blockage and abrasion of the catalyst particles. However, this catalyst imposes relatively high demands on filtration due to its small particle size. Therefore, the development of a microspherical catalyst with both good abrasion resistance and high selectivity is a primary goal for the hydrogenation process.

In carbonyl hydrogenation, it is feasible to improve the activity, selectivity, and stability by adding alkaline earth metal [15]. In fixed-bed hydrogenation, the activity of the catalyst increases by adding rare-earth metal oxides into the catalysts, which inhibits the growth of the alumina crystals at high temperature, increases the surface area of the catalyst, improves the dispersion of $\mathrm{Pd}$, and enhances the catalytic activity effectively [16]. It is reasonable to infer that such non-noble metal additives can also improve the performance of the catalyst in the hydrogenation of AQs.

SINOPEC has independently developed microspherical catalysts for the hydrogenation of AQs in a slurry reactor. The $\mathrm{Pd} / \mathrm{Al}_{2} \mathrm{O}_{3}$ catalyst, modified with non-noble metals, has been proven to exhibit good activity, high selectivity, and high wear resistance in both life tests and pilot tests [17-20]. The catalyst retains its particle integrity, and there is no change in particle size distribution in the pilot-scale unit. The catalyst carrier also exhibits good hydrothermal stability with no apparent change in the structure, which proved that the catalyst developed by SINOPEC has enough mechanical strength. In this novel slurry technology, the hydrogenation efficiency could be up to 12-13 $\mathrm{g} / \mathrm{L}$ (maximum $14.3 \mathrm{~g} / \mathrm{L}$ ), with the oxidation efficiency of $10-12 \mathrm{~g} / \mathrm{L}$.

\section{Working solution}

For hydrogen peroxide production by the AO method, the selectivity depends not only on the hydrogenation catalyst but also on the reaction medium system. This reaction medium, called the working solution in hydrogen peroxide industries, is a kind of homogenous organic solution prepared from AQ dissolved in a mixed solvent. 
Table 1

Features of different polar solvents.

\begin{tabular}{|c|c|c|}
\hline Component/molecular formula & Features & Company \\
\hline $\mathrm{MCA} / \mathrm{C}_{9} \mathrm{H}_{16} \mathrm{O}_{2}$ & $\begin{array}{l}\text { Low solubility in water } \\
\text { High solubility of AHQ and AQ } \\
\text { Large partition coefficient } \\
\text { Density }\left(0.929 \mathrm{~g} / \mathrm{cm}^{3} / 40^{\circ} \mathrm{C}\right) \text { close to that of water } \\
\text { High production cost }\end{array}$ & $\begin{array}{c}\text { Solvay } \\
\text { Arkema }\end{array}$ \\
\hline $\mathrm{DIBC} / \mathrm{C}_{9} \mathrm{H}_{20} \mathrm{O}$ & $\begin{array}{l}\text { High solubility of } A H Q \text { and } A Q \\
\text { Large partition coefficient } \\
\text { Low solubility in water } \\
\text { Low density }\left(0.795 \mathrm{~g} / \mathrm{cm}^{3} / 40^{\circ} \mathrm{C}\right)\end{array}$ & $\begin{array}{l}\text { Solvay } \\
\text { MGC } \\
\text { Dupont } \\
\text { Interox }\end{array}$ \\
\hline $\mathrm{TOP} /\left(\mathrm{C}_{8} \mathrm{H}_{17}\right)_{3} \mathrm{PO}_{4}$ & $\begin{array}{l}\text { High solubility of AHQ and AQ } \\
\text { Large partition coefficient } \\
\text { High boiling point }\left(216^{\circ} \mathrm{C} / 4 \mathrm{mmHg}\right) \\
\text { Low solubility in water } \\
\text { Density }\left(0.909 \mathrm{~g} / \mathrm{cm}^{3} / 40^{\circ} \mathrm{C}\right) \text { close to that of water }\end{array}$ & $\begin{array}{c}\text { Degussa } \\
\text { FMC }\end{array}$ \\
\hline
\end{tabular}

For industrial production, there is rarely only one kind of $\mathrm{AQ}$ used in the working solution [21]. With the increase in the carbon chain length, AQs have relatively high solubility, while they are more liable to cause degradations. Tetrahydroanthraquinone $\left(\mathrm{H}_{4} \mathrm{AQ}\right)$ obtained through the hydrogenation of the aromatic ring also plays the same role as $\mathrm{AQ}$ in the $\mathrm{AO}$ process. Its hydrogenation product, tetrahydroanthrahydroquinone ( $\left.\mathrm{H}_{4} \mathrm{AHQ}\right)$, can be oxidized to hydrogen peroxide as well as $\mathrm{H}_{4} \mathrm{AQ}$. Therefore, a mixture of two or more AQs is commonly used in the working solution.

The solvent system is also a hot research area of hydrogen peroxide production by the AO method. Only when dissolved in appropriate solvents can AQs be hydrogenated and oxidized. It is unlikely that large amounts of both $\mathrm{AQ}$ and hydroanthraquinone (HAQ) can be dissolved in the same organic solvent. Generally, the solvents in the working solution are made up of a non-polar solvent for $\mathrm{AQ}$ and polar one for HAQ that are mutually soluble [24]. Aromatic, aliphatic, and naphthenic hydrocarbons, and their mixtures are used as the solvents of AQs. Domestic industries for hydrogen peroxide production mainly use HA, such as C9. High fatty alcohol, organic acids, and organic acid esters, such as TOP, MCA, TBU, and DIBC, are used to dissolve HAQ. Different solvents have different characteristics, as shown in Table 1 [20-22]. It is showed that polar solvents share certain chemical similarities, such as high solubility of AHQ, large partition coefficient and low solubility in water. However, it is impossible for any solvent to obtain the optimal values of all parameters. For instance, MCA has much higher water content than others, in spite of high solubility of both AHQ and AQ. Different companies choose different solvents to meet various demands like high hydrogenation efficiency, low water solubility, and low organic-matter contents in hydrogen peroxide. Trioctyl phosphate (TOP) are adopted maturely as solvents in domestic plants, with the solubility of AQ given as 120-140 g/L and the hydrogenation efficiency as 7-8 g/L. In oversea plants, the content of AQs in the working solution could be up to $160-180 \mathrm{~g} / \mathrm{L}$ and the hydrogenation efficiency is 10-12 g/L, while using 2-methyl methyl-cyclohexyl acetate (MCA), diisobutylcarbinol (DIBC), and tet-rabutylurea (TBU) instead of TOP [22].

Regardless of the kind of carrier used for the catalyst and the kind of working solution system used for hydrogenation, the selectivity of the catalyst is rarely $100 \%$, as the degradation of AQs is inevitable. Therefore, the regeneration of the degradation products is commonly adopted in industries to recover the AQs, which reduces the loss of the AQs effectively and improves the stability of the catalyst. The most conventional method involves the use of active alumina (namely clay) to regenerate the degradation products, although this method has a noticeable weakness. Due to the physical adsorption of the degradation products, the conversion during regeneration is low, and the regeneration activity decreases quickly with a lifetime of no longer than 2 months. Frequently changing the regeneration catalyst greatly increases the production cost. Moreover, the adsorption of AQs on active alumina is not negligible. In industrial production, the replacement of the regeneration catalyst would cost 2 tons of AQs for a unit of 40,000 metric tons per year [25]. The active alumina utilized in oversea plants has a much higher catalytic activity and selectivity than that in domestic plants. The modification of active alumina with basic oxide is proposed by $\mathrm{Li}$ et al. [26] with a lifetime of 6-20 months. Though the efficiency of the regeneration catalyst is increased considerably, the consumption of active alumina is still not satisfactory. Moreover, the reasons for the increase in the regeneration efficiency are still unclear.

In summary, the production of hydrogen peroxide is a process controlled by trace degradation products. Monitoring and controlling of the degradation products are the key to designing and developing hydrogenation catalysts with high selectivity and regeneration catalysts with improved effectiveness. It is 
very necessary to characterize the types of degradation products and study the regeneration principles, which is the basis for the development of regeneration catalysts with both long lifetime and high activity.

The Liming Institute of Chemical Industry has intensively investigated various degradation products of 2-ethylanthraquinones, identifying 2-ethyl hydroxyl anthrone, 2-ethyl-anthrone, and tetrahydro-epoxy-2-ethylanthraquinone using standard samples [27]. Other extensive studies have also conducted on the degradation products of alkylanthraquinones and the regeneration principles [28-30].

RIPP of SINOPEC has carried out comprehensive studies on qualifying and quantifying the degradation products of 2-ethylanthraquinone and 2-amylanthraquinone using gas chromatography-mass spectrometry (GC-MS) [31]. With the analysis results of the compositions of the working solution, we could gain insights into the regeneration effect on the working solution. Therefore, we can adjust the process and optimize the parameters for hydrogen peroxide production in a rational manner. Moreover, the high-performance regeneration catalysts are also developed for the degradation products of AQs, which can replace the current clay catalyst to make the process more economical [32-34].

\section{Hydrogenation reactors}

The large-scale production of hydrogen peroxide has been in urgent demand in recent years, due to the successful application of green manufacturing technology for caprolactam and propylene oxide developed independently. The annual productivity of a hydrogen peroxide plant should be about 120 kilo metric tons of $100 \%$ product to meet the demand of a caprolactam unit with a capacity of $300 \mathrm{kt} / \mathrm{a}$, and about 220 kilo metric tons for a propylene oxide unit with 300 kilo metric tons per year.

The hydrogenation efficiency of AQs is the primary factor for improving the production capacity. In addition to the hydrogenation catalysts and working solution, factors including the type of the hydrogenation reactors and process conditions have strong impacts on the hydrogenation efficiency and, consequently, the production efficiency. The fixed-bed hydrogenation process is applied in domestic industries, and it is a backward technology abroad. It is difficult to control the hydrogenation extent of AQs due to large temperature increments, bias flow challenges, and existing "hot-spot" temperature in the catalyst bed. Furthermore, excessive hydrogenation increases both the quantity and types of degradation products, lowers the catalyst stability, and restricts hydrogenation efficiency, with further negative effects on capacity expansion. The current production capacity in domestic industries is no more than $50 \mathrm{kt} / \mathrm{a}$ with a limited hydrogenation efficiency of no more than $8 \mathrm{~g} / \mathrm{L}$.

According to the kinetics of $\mathrm{AQ}$ hydrogenation, the hydrogenation reaction is first-order with respect to the hydrogen partial pressure [35-37]. In addition to the internal diffusion resistance, this reaction is also affected by strong external resistance [38]. The reduction of the external diffusion resistance is beneficial for the thorough reaction and acceleration of hydrogenation, thus improving hydrogenation efficiency.

To reduce the adverse effects caused by external diffusion resistance, channeling, and bias flow, several methods are adopted in domestic industries to improve the reaction efficiency, such as series operation on multiple-stage reactors [39] and intensification of the inner structure for vapor-liquid maldistribution. Supergravity technology has been used as an enhanced technology for micromixing and mass transfer in recent years [40]. It is reported that the space-time yield per pass in the hydrogenation of $\mathrm{AQ}$ could be increased considerably by applying this novel method instead of other fixed-bed technologies. However, there is no related report yet on its commercial application due to the significant demand on equipment manufacture and hydrogenation ability of the catalysts.

Intensification methods mitigate rather than eliminate the problems in the fixed-bed reactor. In contrast, the slurry-bed reactor with excellent temperature uniformity has great advantages in mass and heat transfer, and the degradation of AQs can be controlled effectively. Slurry-bed reactor technology abroad can achieve high hydrogenation efficiencies up to 18 $\mathrm{g} / \mathrm{L}$ at a maximum production capacity of 250 kilo metric tons per year (of $100 \%$ product). Degussa developed a novel hydrogenation reactor with a certain number of loop pipes [41]. Narrow channels can be constructed in this reactor so that the working solution with catalysts can be mixed with hydrogen, after which hydrogenation is accomplished in a suspension state by entering into the reactor from the bottom. This company also developed a filter system by separating the working solution from the catalysts using filters [42]. The filter system is back-flushed with the working solution without catalysts or a solvent-containing working solution periodically. The filter drum with an average pore diameter of $5-100 \mu \mathrm{m}$ is made of carbon, metal, or ceramics. A single- and multi-layer ceramic filter membrane with an average pore diameter of $1-10 \mu \mathrm{m}$ is deposited on one side of the filter drum. Despite the increase in the product yield, its application is also limited by many issues, including its complex construction, high energy consumption, high equipment investment, and short lifetime of the catalysts.

A reaction-filtration system developed independently by SINOPEC RIPP [20,43] has evident advantages in large-scale plants due to its simple structure and outstanding performance in mass and heat transfers. It successfully avoids many of the problems associated with large-scale production on the fixed-bed reactors, such as the bias flow, channeling, and catalyst hardening. The system runs smoothly and can achieve a high hydrogenation efficiency of more than $11 \mathrm{~g} / \mathrm{L}$ in a pilot application.

\section{Environmental protection}

As a kind of green chemical, hydrogen peroxide decomposes into water and oxygen without secondary pollution. However, the production of $\mathrm{H}_{2} \mathrm{O}_{2}$ through the $\mathrm{AQ}$ method is not eco-friendly. Apart from the tons of solid waste produced in the regeneration process of the working solution, quite a significant amount of exhaust waste containing aromatics is dis- 
charged as air is compressed into the system to offer enough oxygen in the oxidation process [44].

Decreasing the temperature of the exhaust gas can condenses aromatics, which seems to be an effective method to recover the solvent. However, the aromatic content in waste air is still about $2000 \mathrm{mg} / \mathrm{m}^{3}$ at the temperature of $5{ }^{\circ} \mathrm{C}$, far exceeding the national standard of $120 \mathrm{mg} / \mathrm{m}^{3}$. Therefore, many measures have been taken for the further recovery of aromatics, e.g., chemical absorption, physical absorption, expansion by a turbine, and adsorption technique. Currently, expansion by a turbine in conjugation with adsorption by active carbon fiber is commonly used. The wastewater generated from the oxidation process is also a severe problem. The transfer of a certain amount of water into the oxidation reactor by compressed air is inevitable, which would absorb hydrogen peroxide. As a result, the water phase is formed at the bottom of the oxidation reactor. With the assumption of an ambient temperature of 30 ${ }^{\circ} \mathrm{C}$ and isothermal compression in the air compressor, $120.3 \mathrm{~kg}$ of condensed water is produced per hour for a unit production of $45 \mathrm{kt} / \mathrm{a}$.

Recent studies have attempted to reduce exhaust emission by improving the oxidation efficiency, which does not effectively eliminate the source of the air pollution $[45,46]$. A novel oxidation method that does not involve waste gas discharge and solvent recovery has been invented for hydrogen peroxide production by SINOPEC RIPP (Fig. 2). In this process, the oxygen content in the reactor is controllable, and the amount of residue liquid in the reactor is also decreased. With zero exhaust emission, the recovery technology of aromatic compounds is no longer necessary. Similar to the case in the conventional oxidation process, the OS with a low content of hydrogen peroxide, as well as the exhaust gas, is obtained. Furthermore, the exhaust gas is compressed and returned to the reactor rather than discharged. To ensure continuous oxygen supply, an oxygen-rich gas mixture is continuously added to the recycle gas according to the consumption of oxygen.

Due to the absence of waste gas discharge and solvent recovery, the generation of organic solvent waste and environ-

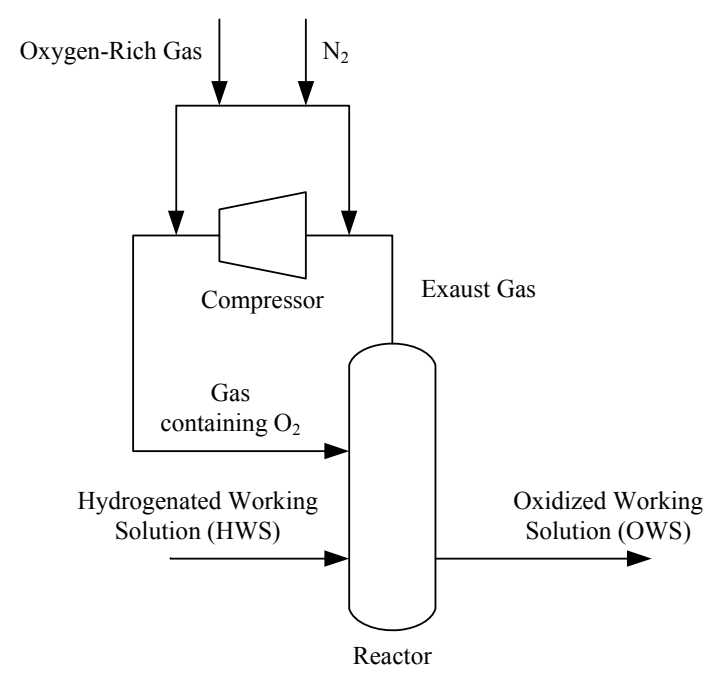

Fig. 2. The improved technological flow chart of hydrogen peroxide production by the $\mathrm{AO}$ method. mental pollution can be avoided. Moreover, the amount of the oxidized residue liquid has also decreased owing to the considerably lower humidity of the mixed gas than the compressed air. In summary, this method is safe, energy-saving, and environmentally friendly. This innovation in hydrogen peroxide production solves the most important problem of environmental protection and, thus, paves the way toward a green process.

\section{Direct synthesis of hydrogen peroxide}

As the mainstream route for the production of hydrogen peroxide, the AO method is a mature industrial technology, whose high efficiency and high safety are attributed to the absence of direct contact between hydrogen and oxygen $[47,48]$. However, the technology still faces several challenges, such as high energy consumption, high equipment input, and environmental pollution caused by the large amount of organic solvents used in the process mentioned above. Compared with the traditional process, the direct synthesis of hydrogen peroxide (DSHP) from molecular hydrogen and oxygen is a highly atomically efficient and environmentally friendly alternative route that has attracted continuous interests due to its significance from both fundamental and practical viewpoints [49-51].

The DSHP process is a complex three-phase reaction $\left(\mathrm{H}_{2} / \mathrm{O}_{2}\right.$ mixed gas phase as reactants, solid-supported metal catalysts, and solvent as the intermediate medium). Aside from the target reaction, there are three side reactions, as shown in Fig. 3. According to the thermodynamic data, water is the thermodynamically favorable product, whereas hydrogen peroxide is only an intermediate product. Therefore, selectivity is a priority when designing the catalyst to achieve high productivity of hydrogen peroxide while avoiding unwanted, facile water formation. In addition, a large amount of inert gas, as the dilution gas, needs to be added and circulated due to the potential safety hazards associated with the direct contact of $\mathrm{H}_{2}$ with $\mathrm{O}_{2}$, which increases the difficulty of operation control and greatly reduces the synthesis efficiency.

To solve these two major problems of low yield and potential safety hazards, since the first patent proposed in 1914 [52], researchers have devoted significant efforts to the catalyst design, reaction conditions, reactor improvements, etc. From the literature, Pd has been commonly recognized as an optimal metal that exhibits relatively higher performance for the DSHP than other transition metals [51,53-55]. However, the relationship between the active sites for hydrogen peroxide formation and the role of the surface species, $\mathrm{Pd}^{0}$ and $\mathrm{Pd}^{2+}$, remains controversial. It has been evidenced that $\mathrm{Pd}^{0}$ and $\mathrm{Pd}^{2+}$ co-exist on the surface and synergistically catalyze the reaction. $\mathrm{Pd}^{0}$ is conducive for the adsorption and dissociation of $\mathrm{H}_{2}$ and also affects the conversion directly, while $\mathrm{Pd}^{2+}$ is related to the selectivity of hydrogen peroxide [56-59]. Therefore, several methods have been introduced to improve the catalytic performance, such as by further surface treatment by $\mathrm{HClO}_{4}, \mathrm{HNO}_{3}$, and air to adjust the surface $\mathrm{Pd}$ species ratio, or addition of a second metal such as Au [60-63], Pt [64,65], Sn [66], Ru [67], Ir $[68]$, or $\mathrm{Rh}[69,70]$ to Pd to regulate the electronic and geomet- 
rical structures of Pd. Moreover, the intrinsic properties of the support, such as the isoelectric point and acidity/basicity, are another important factor that affects the catalytic performance. The activated carbon with a relatively low isoelectric point shows a low $\mathrm{H}_{2} \mathrm{O}_{2}$ decomposition rate, while the alkaline carrier, $\mathrm{MgO}$, with a relatively high isoelectric point, shows a high $\mathrm{H}_{2} \mathrm{O}_{2}$ hydrogenation rate [71]. The support is modified by acid pre-treatment $\left(\mathrm{HNO}_{3}\right)$, halogen $(\mathrm{Cl}, \mathrm{Br})$ doping, or nitrogen doping, which could affect the dispersion, electronic structure, or surface arrangement of the metal particles on the catalysts, thus effectively inhibiting side reactions and promoting the formation of hydrogen peroxide [72,73].

The DSHP process contains three phases (gas-liquid-solid); thus, the product yield is affected by the mass transfer rates of the $\mathrm{H}_{2}$ and $\mathrm{O}_{2}$ reactants through the liquid solvent to the catalyst surface. In the design of the experiment, on the one hand, one can increase the system pressure or choose an appropriate mixture solution to improve the solubilities of $\mathrm{H}_{2}$ and $\mathrm{O}_{2}$ in an intermediate medium. On the other hand, the solvent with reduced viscosity and low surface tension is chosen to reduce the mass transfer resistance [6]. Thus, water, methanol, or their mixed solution is often chosen as the reaction medium due to safety and practicability concerns. Furthermore, acid $\left(\mathrm{H}^{+}\right)$ $[74,75]$ and halogen ions $\left(\mathrm{Cl}^{-}, \mathrm{Br}^{-}\right)[76,77]$ were added to the reaction medium, and they could significantly increase the yield of hydrogen peroxide over the mono-Pd catalyst. This is because $\mathrm{H}^{+}$inhibits the decomposition of hydrogen peroxide. In addition, the protons play an active role in the formation of hydrogen peroxide according to the proton-electron mechanism, while halogen ions, $\mathrm{Cl}^{-}$and $\mathrm{Br}^{-}$, could block or selectively poison the active sites for side reactions, thus significantly improving the selectivity toward hydrogen peroxide. However, adding acid and halogen to the reaction solution will also corrode the metallic reactor and lead to the loss of active components, which would seriously reduce the catalyst working time and limit its industrial application [57].

Considering the safety risks of the DSHP process, there are more strict requirements put forward for the reaction system design. Currently, several reactors have been reported, each with its own characteristics: the high-pressure batch reactor $[60,61]$ is the most commonly used and the closest to industrial

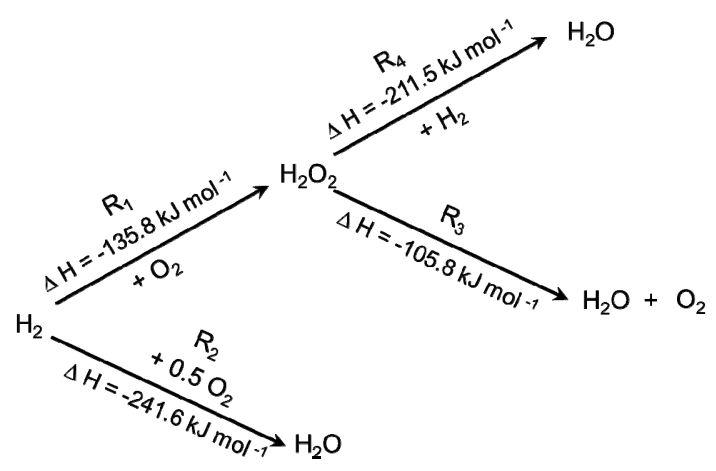

Fig. 3. Reaction network in the DSHP from molecular hydrogen and oxygen. application; the semi-continuous reactor [74,75] shows high safety and low energy consumption; the trickle-bed reactor [78] could achieve continuous production but with low yield. The microchannel reactor [62] and membrane reactor could prevent $\mathrm{H}_{2}$ from interacting with $\mathrm{O}_{2}$ directly; thus, they have a high safety factor and high cost.

The selective oxidation using molecular $\mathrm{O}_{2}, \mathrm{H}_{2} \mathrm{SO}_{4}$, and $\mathrm{Cl}_{2}$ has some problems, such as high energy and capital demands under harsh conditions in current industrial processes [79-81]. A promising alternative route that attracts more attention is the combination of the in situ synthesis of hydrogen peroxide with selective oxidation reactions, i.e., Fenton process [82-85], methane valorization to methanol [86], cyclohexane [87-90] and propylene oxidation [91,92], and so on, which has significant environmental and economic advantages as the need to store a large amount of hydrogen peroxide is eliminated. However, a relatively low $\mathrm{H}_{2} \mathrm{O}_{2}$ yield in the presence of the stabilizing agent, the negative effects of the stabilizing agent on the lifetime of the catalyst and reactor, and the co-existence of active sites on the catalyst surface for oxidation and direct synthesis reactions are all significant problems associated with the catalyst and reaction design at the current stage. Numerous experiments in our group have been focused on the design of new catalysts to improve $\mathrm{H}_{2} \mathrm{O}_{2}$ productivity without requiring acid or halide additives. Increased efforts also could be devoted to increasing the $\mathrm{H}_{2} \mathrm{O}_{2}$ concentration to improving the competitiveness of this process against other industrial processes. It is expected that the commercialization of the DSHP will be realized through the collaboration of theoretical research, experiment design, and engineering exploration in the near future.

\section{Conclusions}

Hydrogen peroxide production through AQ is applied in almost all domestic industries. Despite the high technical maturity, many aspects of this process have not been optimized, including the hydrogenation catalysts, working solution system, hydrogenation reactor, and environmental protection, which require effective solutions to scale up the process. With original innovation on every aspect mentioned above, different technologies for hydrogen peroxide production by the AQ process have been developed by SINOPEC with independent intellectual property rights. In addition, SINOPEC RIPP has been conducting research on the combination of the direct synthesis of $\mathrm{H}_{2} \mathrm{O}_{2}$ with a chemical reaction system, which is a developing concept in the future of $\mathrm{H}_{2} \mathrm{O}_{2}$ production.

\section{References}

[1] P. C. Foller, R. T. Bombard, J. Appl. Electrochem., 1995, 25, 613-627.

[2] G. C. Zhang, Hydrogen Peroxide Production Technology, 1st ed., Chemical Industry Press, Beijing, 2012, 84-85.

[3] Y. Y. Guo, C. N. Dai, Z. G., B. H. Chen, X. C. Fang, Catal. Today, 2016, 276, 36-45.

[4] H. B. Li, B. Zheng, Z. Y. Pan, B. N. Zong, M. H. Qiao, Front. Chem. Sci. Eng., 2018, 12, 124-131.

[5] M. Yang, Dalian University of Technology, Dalian, 2010, 3-4. 


\section{Graphical Abstract}

Chin. J. Catal., 2020, 41: 1039-1047 doi: 10.1016/S1872-2067(20)63562-8

\section{Advances in the production technology of hydrogen peroxide}

Guohua Gao, Yanan Tian, Xiaoxiao Gong, Zhiyong Pan,

Keyong Yang, Baoning Zong *

Research Institute of Petroleum Processing, Sinopec

This review summarizes the breakthroughs of the $\mathrm{H}_{2} \mathrm{O}_{2}$ production technology through anthraquinone auto-oxidation, as well as technical prospect and scientific challenges associated with the direct synthesis of $\mathrm{H}_{2} \mathrm{O}_{2}$.

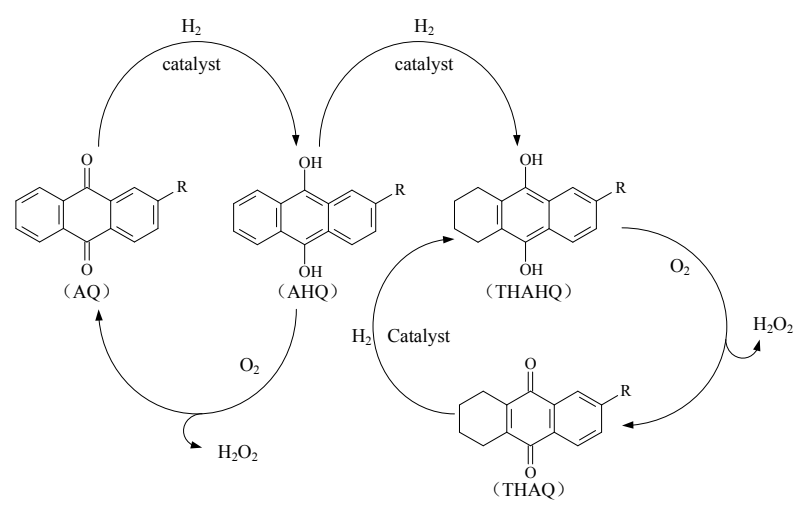

[6] C. Samanta, Appl. Catal. A, 2008, 350, 133-149.

[7] J. W. Han, East China University of Science and Technology, Shanghai, 2001.

[8] K. M. Makar, US Patent 4061 598, 1977.

[9] H. B. Copelin, US Patent 4240 933, 1980.

[10] K. Ogasawara, T. Kato, N. Okuda, T. Konishi, K. Kato, CN Patent 1165111A, 1980.

[11] T. Yamaguchi, T. Ohashi, JP Patent 170485, 2001.

[12] V. Mathieu, P. Pennetreau, N. Vanlautem, US Patent 6306 359, 2001.

[13] C. C. Hu, Chem. Propel. Polym. Mater., 2004, 2(3), 1-4.

[14] A. Drelinkiewicz, A. Pukkinen, R. Kangas, R. Laitinen, Catal. Lett., 2004, 94, 157-170.

[15] R. Kosydar, A. Drelinkiewicz, E. Lalik, J. Gurgul, Appl. Catal. A, 2011, 402, 121-131.

[16] R. Wang, C. C. Lin, T. W. Chen, J. X. Lin, S. L. Mao, J. Fuzhou Univ. (Nat. Sci. Edt.), 2005, 33, 391-394.

[17] X. K. Meng, X. B. Chen, X. H. Mu, X. X. Zhang, X. Wang, B. N. Zong, E. Z. Min, CN Patent 1261347 C, 2003.

[18] X. K. Meng, CN Patent 1541 766, 2004.

[19] X. K. Meng, X. B. Chen, X. H. Mu, X. X. Zhang, X. Wang, B. N. Zong, CN Patent 1317253 C, 2004.

[20] Z. Y. Pan, G. H. Gao, K. Y. Yang, B. N. Zong, Sin. Chin., 2015, 45, 541-546.

[21] L. Cao, K. J. Yang, W. T. Shi, R. lv, Z. W. Wang, Chem. Eng. (China), 2017, 45(2), 74-78.

[22] H. Yang, G. Z. Qing, G. C. Liu, X. Yu, Y. Xie, CN Patent 104085859A, 2014.

[23] X. S. Wang, X. M. Xia, Z. X. Xu, X. Y. Chen, CN Patent 101798065 , 2010.

[24] M. Li, Y. F. Li, Fine Chem. Raw Mater. Intermediate, 2018, 10, 12-16.

[25] Y. D. Li, W. B. Zhang, G. Y. Yu, Chem. Propel. Polym. Mater., 2003, 1(5), 48-49.

[26] D. Q. Li, Z. T. Guo, J.T. Feng, Y. J. Feng, CN Patent 102728338 , 2012.

[27] Q. L. Chen, Inorg. Chem. Ind., 2002, 34, 15-18.

[28] X. T. Li, H. J. Su, G. Y. Ren, S. D. Wang, Appl. Catal. A, 2016, 517, 168-175.

[29] E. Santacesaria, M. Di Serio, R. Velotti, U. Leone, J. Mol. Catal., 1994,
94, 37-46.

[30] F. Sandelin, P. Oinas, T. Salmi, P. Juhani, H. Haario, Ind. Eng. Chem. Res., 2006, 45, 986-992.

[31] Y. Q. Zhang, G. H. Gao, K. Y. Yang, B. N. Zong, G. T. Xu, Chin. J. Chromatogr., 2019, 37, 432-437.

[32] W. J. Wang, Z. Y. Pan, B. Zheng, G. Guo, K. Yang, X. Mu, B. Zong, CN Patent 106540685A, 2015.

[33] W. J. Wang, Z. Y. Pan, B. Zheng, G. Guo, K. Yang, X. Mu, B. Zong, CN Patent 106542502A, 2015.

[34] W. J. Wang, Z. Y. Pan, B. Zheng, G. Guo, K. Yang, X. Mu, B. Zong, Pet. Process. Petrochem., 2016, 47, 103-106.

[35] J. M. Campos-Martin, G. Blanco-Brieva, J. L. G. Fierro, Angew. Chem. Int. Ed., 2006, 45, 6962-6984.

[36] T. Berglin, N. H. Schoeoen, Ind. Eng. Chem. Process Des. Dev., 1981, 20, 615-621.

[37] E. Santacesaria, R. Ferro, S. Ricci, S. Carra, Ind. Eng. Chem. Res., 2002, 26, 155-159.

[38] E. Santacesaria, P. Wilkinson, P. Babini, S. Carra, Ind. Eng. Chem. Res., 1988, 27, 780-784.

[39] X. Q. Wang, H. P. Zhang, T. L. Cheng, L. Wang, Chem. Propel. Polym. Mater, 2017, 15(2), 48-51.

[40] J. Z. Lu, H. J. Zhou, Q. Xu, Petro. Sci. Bull., 2016, 1, 503-511.

[41] P. Korl, B. Maurer, US Patent, 09982 108, 2001.

[42] H. Eickhoff, R. Schirrmacher, K. Margartz, H. M. Huber, R. Goedecke, CN Patent 1081 649, 1994.

[43] G. H. Gao, K. Y. Yang, H. B. Li, Z. Y. Pan, B. Zheng, B. N. Zong, CN Patent 201320492007, 2013.

[44] Y. C. Guo, M. Zhang, Y. P. Zhao, J. H. Cui, Chem. Propel. Polym. Mater. 2017, 15(5), 79-81.

[45] X. L. Liu, Inorg. Chem. Ind., 2009, 41(01), 41-43.

[46] X. H. Du, W. B. Zhou, Chem. Production Technol, 2013, 20(5), $52-55$.

[47] H. J. Rledl, G. Pfleiderer, I. G. Farbenindustrie AG, 1939.

[48] L. J. Thenard, Ann. Chim. Phys., 1818, 8, 306-312.

[49] R. Arrigo, M. E. Schuster, S. Abate, G. Giorgianni, G. Centi, S. Perathoner, S. Wrabetz, V. Pfeifer, M. Antonietti, R. Schlögl, ACS Catal., 2016, 6, 6959-6966.

[50] B. Z. Hu, W. P. Deng, R. S. Li, Q. H. Zhang, Y. Wang, F. Delplanque-Janssens, D. Paul, F. Desmedt, P. Miquel, J. Catal., 2014, 319, 15-26. 
[51] M. Seo, D. W. Lee, S. S. Han, K. Y. Lee, ACS Catal., 2017, 7, 3039-3048.

[52] H. Henkel, W. Weber, US1108752 A, 1914.

[53] D. P. Dissanayake, J. H. Lunsford, J. Catal., 2002, 206, 173-176.

[54] J. W. Lee, J. K. Kim, T. H. Kang, E. J. Lee, I. K. Song, Catal. Today, 2017, 293-294, 49-55.

[55] Y. Han, J. H. Lunsford, J. Catal., 2005, 230, 313-316.

[56] R. Todorovic, R. J. Meyer, Catal. Today, 2011, 160, 242-248.

[57] D. P. Dissanayake, J. H. Lunsford, J. Catal., 2003, 214, 113-120.

[58] S. Chinta, J. H. Lunsford, J. Catal., 2004, 225, 249-255.

[59] A. Staykov, T. Kamachi, T. Ishihara, K. Yoshizawa, J. Phys. Chem. C, 2008, 112, 19501-19505.

[60] J. K. Edwards, G. J. Hutchings, Angew. Chem. Int. Ed., 2008, 47, 9192-9198.

[61] J. K. Edwards, E. N. Ntainjua, A. F. Carley, A. A. Herzing, C. J. Kiely, G. J. Hutchings, Angew. Chem. Int. Ed., 2009, 48, 8512-8515.

[62] V. Paunovic, V. Ordomsky, M. F. N. D'Angelo, J. C. Schouten, T. A. Nijhuis, J. Catal., 2014, 309, 325-332.

[63] J. K. Edwards, J. Pritchard, L. Lu, M. Piccinini, G. Shaw, A. F. Carley, D. J. Morgan, C. J. Kiely, G. J. Hutchings, Angew. Chem. Int. Ed., 2014, 53, 2381-2384.

[64] Q. S. Liu, J. C. Bauer, R. E. Schaak, J. H. Lunsford, Appl. Catal. A, 2008, 339, 130-136.

[65] J. Xu, L. Ouyang, G. J. Da, Q. Q. Song, X. J. Yang, Y. F. Han, J. Catal., 2012, 285, 74-82.

[66] S. J. Freakley, Q. He, J. H. Harrhy, L. Lu, D. A. Crole, D. J. Morgan, E. N. Ntainjua, J. K. Edwards, A. F. Carley, A. Y. Borisevich, C. J. Kiely, G. J. Hutchings, Science, 2016, 351, 965-968.

[67] E. N. Ntainjua, S. J. Freakley, G. J. Hutchings, Top. Catal., 2012, 55, 718-722.

[68] T. Deguchi, H. Yamano, S. Takenouchi, M. Lwamoto, Catal. Sci. Technol., 2018, 8, 1002-1015.

[69] V. R. Choudhary, C. Samanta, T. V. Choudhary, Appl. Catal. A, 2006, 308, 128-133.

[70] J. V. Weynbergh, J. P. Schoebrechts, J. C. Colery, US5447706, 1995.

[71] K T. Chuang, US 5082647, 1992; K. T. Chuang, B. Zhou, WO 9314025, 1993; US 5846898, 1998.
[72] S. Park, T. J. Kim, Y. Chung, S. H. Oh, I. K. Song, Catal. Lett., 2009, 130, 296-300.

[73] A. Rodriguez-Gomez, F. Platero, A. Caballero, G. Colón, Mol. Catal., 2018, 445, 142-151.

[74] V. R. Choudhary, C. Samanta, J. Catal., 2006, 238, 28-38.

[75] V. R. Choudhary, C. Samanta, P. Jana, Appl. Catal. A, 2007, 317, 234-243.

[76] P. Centomo, C. Meneghini, S. Sterchele, A. Trapananti, G. Aquilanti, M. Zecca, Catal. Today, 2015, 248, 138-141.

[77] P. Biasi, S. Sterchele, F. Bizzotto, M. Manzoli, S. Lindholm, P. Ek, J. Bobacka, J. P. Mikkola, T. Salmi, Catal. Today, 2015, 246, 207-215.

[78] P. Biasi, F. Menegazzo, F. Pinna, K. Eränen, P. Canu, T. O. Salmi, Ind. Eng. Chem. Res., 2010, 49, 10627-10632.

[79] R. Kumar, S. Sithambaram, S. L. Suib, J. Catal., 2009, 262, 304-313.

[80] G. Blanco-Brieva, M. C. Capel-Sanchez, M. Pilar de Frutos, A. Padilla-Polo, J. M. Campos-Martin, J. L. G. Fierro, Ind. Eng. Chem. Res., 2008, 47, 8011-8015.

[81] R. A. Periana, D. J. Taube, S. Gamble, H. Taube, T. Satoh, H. Fujii, Science, 1998, 280, 560-564.

[82] M. Triki, S. Contreras, F. Medina, J. Sol-Gel Sci. Technol., 2014, 71, 96-101.

[83] Y. Liu, Z. Yu, Y. Hou, Z. Peng, L. Wang, Z. Gong, J. Zhu, D. Su, Catal. Commun., 2016, 86, 63-66.

[84] Y. Qin, M. Sun, H. Liu, J. Qu, Electrochim. Acta., 2015, 186, 328-336.

[85] M. S. Yalfani, A. Georgi, S. Contreras, F. Medina, F. D. Kopinke, Appl. Catal. B, 2011, 104, 161-168.

[86] M. Lin, T. Hogan, A. Sen, J. Am. Chem. Soc., 1997, 119, 6048-6053.

[87] M. Rezaei, A. Najafi Chermahini, H. A. Dabbagh, Chem. Eng. J., 2017, $314,515-525$.

[88] P. Borah, A. Ramesh, A. Datta, Catal. Commun., 2010, 12, 110-115.

[89] E. V. Spinace, H. O. Pastore, U. Schuchardt, J. Catal., 1995, 157, 631-635.

[90] C. Shi, B. Zhu, M. Lin, J. L, R. W. Catal. Today, 2011, 175, 398-403.

[91] B. S. Uphade, M. Okumura, S. Tsubota, M. Haruta, Appl. Catal. A, 2000, 190, 43-50.

[92] T. A. Nijhuis, M. Makkee, J. A. Moulijn, B. M. Weckhuysen, Ind. Eng. Chem. Res., 2006, 45, 3447-3459.

\section{过氧化氢生产工艺进展}

\section{高国华，田雅楠，巩笑笑，潘智勇，杨克勇，宗保宁*}

中国石油化工股份有限公司石油化工科学研究院, 北京 100083

摘要: 生产过氧化氢通常有电解法、葱醌法、异丙醇法以及氧阴极还原法等. 目前全世界总产量的 $95 \%$ 以及国内总产量的 99\%的过氧化氢都是采用葱醌法生产的. 在更先进的生产过氧化氢的技术出现之前, 萝醌法仍将是今后一段时期生产过氧 化氢最普遍的一种方法.

葱醌加氢工艺有固定床和浆态床两种, 国内仍采用较为落后的固定床工艺, 而国外基本都采用浆态床工艺. 固定床存 在床层温升大、易偏流、有局部热点等缺陷, 易导致葱醌过度加氢, 降解物种类和数量增多, 降低了催化剂稳定性, 限制了 加氢单元的氢效, 生产装置难以大型化. 而浆态床工艺具有传质传热好、温度和气液固三相分布均匀等优势, 是过氧化氢 生产技术的发展趋势. 浆态床反应器对催化剂的选择性具有更高的要求. 因此, 浆态床加氢技术的研发核心是开发兼有耐 磨性和高选择性的微球催化剂. 中国石化自主开发了具有高活性、高选择性和良好稳定性的葱醌加氢微球催化剂, 并对其 活性和选择性进行了寿命试验和中试评价. 中试结束后结粒度分布基本保持不变;载体水热稳定性好, 使用过程结构没有 发生明显变化. 证明该催化剂机械强度高、耐磨性能好, 能够满足浆态床使用要求. 在新生产工艺中采用自主开发的新型 浆态床反应器, 具有优异的传质、传热效率; 催化剂粒径小, 完全克服了固定床反应器在规模稍大时存在的偏流、沟流、 触媒板结等缺点, 氢化效率可长期稳定在 $11 \mathrm{~g} / \mathrm{L}$ 以上; 副反应少, 氢化降解物大幅度减少, 极大地减轻后续降解物再生负担.

在实际工业生产中, 葸醌加氢选择性无法实现 $100 \%$, 因此工作液中难以避免生成降解物, 通常采用白土再生手段, 使 其再转变为葱醌. 但再生剂更换频繁, 大大增加了生产成本, 同时损失被物理吸附上去的昂贵的葱醌. 因此, 十分有必要对 
葱醌加氢的降解物种类进行定性识别并研究其再生机理, 并在此基础上开发兼有长寿命和高活性的萝醌降解物再生催化 剂. 中国石化采用GC-MS对乙基葱醌和戊基葱醌多种降解物进行比较全面的定性和定量研究, 通过分析葱醌工作液组成 准确推测工作液再生效果, 便于及时调整双氧水生产工艺工艺流程和优化参数; 并自主开发高性能的葱醌加氢降解物再 生催化剂, 可替代现有效率低下的白土床, 显著提高装置经济性.

为有效解决葱醌法生产中氧化废气的排放问题, 中国石化发明一种无尾气排放、无需溶剂回收、氧含量可控、可减少 氧化残液量的葱醌法生产过氧化氢的氧化方法, 从源头上解决葱醌法生产双氧水装置的最大环保问题, 它的应用将使葱醌 法生产双氧水装置朝着绿色环保迈出一大步.

目前葱醌法生产 $\mathrm{H}_{2} \mathrm{O}_{2}$ 虽然具有技术成熟、单程产率高、安全性高等优点, 依旧存在投资高、工艺流程复杂, 以及大量 使用有机溶剂带来的产品污染、环境污染问题. 与其相比, $\mathrm{H}_{2}$ 和 $\mathrm{O}_{2}$ 直接合成 $\mathrm{H}_{2} \mathrm{O}_{2}$ (以下称为DSHP) 技术的原子经济性高, 并 且污染少、环境友好. 但由于反应过程中 $\mathrm{H}_{2}$ 和 $\mathrm{O}_{2}$ 直接接触, DSHP工艺存在一定的安全隐患. 在反应过程中需要充入大量惰 性气体稀释并循环, 导致DSHP工艺效率低, 操作及控制难度大. 该反应所使用的Pd基催化剂, 既有利于 $\mathrm{H}_{2} \mathrm{O}_{2}$ 的生成, 也利 于三个副反应的发生: $\mathrm{H}_{2} \mathrm{O}$ 的生成、 $\mathrm{H}_{2} \mathrm{O}_{2}$ 的后续加氢及分解, 导致产品选择性和产率较低. 加入酸和卤素等稳定剂虽然可以 显著提高产率, 但存在设备腐蚀、催化剂活性组分流失等问题, 严重影响催化剂的使用寿命. 中国石化目前已经开始布局 研发DSHP技术, 在提高 $\mathrm{H}_{2} / \mathrm{O}_{2}$ 反应的本质安全性、研发 $\mathrm{H}_{2} \mathrm{O}_{2}$ 精准合成的催化材料和提高 $\mathrm{H}_{2} \mathrm{O}_{2}$ 产能等方面做了大量的研究. 可以预见, 通过理论研究、实验设计和工程开发相结合, 在不远的未来能够实现DHSP技术的工业应用.

目前国内双氧水几乎全部采用葱醌法生产. 虽然葱醌法工艺已很成熟, 但在多个技术环节, 特别是葱醌加氢催化剂、 工作液体系、加氢反应器和环保等方面, 存在非常大改进提升的空间. 这些问题是实现装置大型化必须解决的. 中国石化 在这几个方面都自主开发了创新技术, 形成了国内全新的拥有自主知识产权的生产过氧化氢的成套技术. 作为最直接、最 环保、最经济的生产过氧化氢的方法, 氢氧直接合成技术与化工反应过程耦合, 是未来过氧化氢生产和应用的发展方向, 中 国石化也已经开始在此方面进行研究和布局.

关键词: 过氧化氢; 葱醌法; 葱醌加氢; 加氢催化剂; 生产工艺

收稿日期: 2019-10-12. 接受日期: 2019-12-04. 出版日期: 2020-07-05.

*通讯联系人. 电话: (010)82368011; 电子信箱: zongbn.ripp@sinopec.com

基金来源：国家重点研发计划(2016YFB0301600).

本文的电子版全文由Elsevier出版社在ScienceDirect上出版(http://www.sciencedirect.com/science/journal/18722067). 